\title{
Roar of the Crowd: Noise-Related Safety Concerns in Sport
}

\author{
Robin Ammon, Kimberly Mahoney, Gil Fried, \\ Khadija Al Arkoubi, and Dale Finn
}

\begin{abstract}
In sport the safety of staff, participants and spectators is of the utmost importance. Therefore, sport venue and event managers should take every precaution to address safety concerns while planning for and executing events or activities. While venue managers have a legal duty to protect fans and participants, federal regulations exist to ensure a safe workplace for all employees, including those at a sports event. This is a conceptual article intended to assist practitioners to identify potentially unexpected hazards within the work environment, as well as strategies to eliminate or manage them. The authors examine existing federal regulations, current research associated with hearing/noise-related concerns and specific research undertaken in the sport environment. The article concludes with recommended prevention strategies for facility and event managers to assist them in meeting their professional and legal obligations.
\end{abstract}

Most sport enthusiasts love to hear the roar of the crowd and, at times, the slogan "let's make some noise" is used to help motivate the home team. Subsequently some sport venues are known for how much noise they generate. On September 29, 2014 at Arrowhead Stadium, during a National Football League (NFL) game between the Kansas City Chiefs and the New England Patriots, a Guinness World Record for crowd noise was set when decibel levels reached 142.2 breaking the record 137.6 set in December 2013 at a Seattle Seahawks and New Orleans Saints game. Coaches in Arrowhead remarked they could feel the ground shaking and later heard ringing in the ear not covered by their headset (Dolich, 2014).

Music and sound have become so integral to the fan experience that recent decisions involving the Americans with Disability Act mandate stadiums and arenas to provide closed captions for the hearing impaired. This requires text from the music or PA announcements to be placed on the facility's scoreboards (Matador Sports, 2011). However, not all noise in sports is enjoyable. Fans may dislike or be sensitive to too much noise, which may negatively impact their experience.

Ammon (robin.ammon@used.edu) is with the Dept. of Kinesiology and Sport Science, University of South Dakota, Vermillion, SD. Mahoney and Fried are with the Dept. of Sport Management, University of New Haven, West Haven, CT. Al Arkoubi and Finn are with the Dept. of Management, University of New Haven, West Haven, CT. 
Research has shown that hearing loss can be cumulative and irreversible. The amplitude and duration of noise will increase the chance of irreversible inner ear damage. Various studies indicate the risk of injury will also vary with frequency (Plontke \& Zenner, 2004). As a result, children accompanying parents who are season ticket holders can sustain permanent hearing as a result of attending games with their parents.

This concern may also impact employees working at a sport facility or within the context of a sport activity. For example, individuals working at a motorsport racetrack may be exposed to excessive, sustained noise from the racecars when working in the pit area. Sport officials may be susceptible to excessive noise from whistles, as well as crowd noise. While blaring aerobics music is often used in fitness studios to motivate the participants, it may be a cause for concern for the instructors and other employees who are exposed for extended periods of time.

Sound is measured through units called decibels $(\mathrm{dB})$. Certain levels of decibels are safe, but others can cause immediate damage. Anything above $80 \mathrm{~dB}$ can cause discomfort. A weighted decibel (dBA) is an expression of the level of noise as the human ear perceives it. It only takes eight hours at noise levels of $80 \mathrm{dBA}$ to cause irreversible damage to a person's hearing (Kujawa \& Liberman, 2009). Unfortunately, some individuals do not realize how loud music and excessive noise can damage one's hearing and potentially lead to permanent hearing loss. Employees in a variety of settings may face serious short and long-term health problems. Therefore, it is imperative employees and their employers are aware of these risks and their respective responsibilities to protect themselves and others.

This article is written to help develop a more accurate understanding of the types of noises that may induce hearing loss. Two legal cases are presented along with their implications for employees in sports and numerous examples pertaining to the risks produced by excessive noise in sporting events and fitness centers are reviewed. Through analyzing these relevant cases, examining federal regulations, and reviewing industry standards, as well as considering the conclusions developed from a variety of research sources, the authors will provide a clearer picture of what constitutes appropriate noise levels in the sport industry. The article concludes with specific strategies to help make the sport workplace safer.

\section{Legal Cases}

A thorough search of cases using LexisNexis was undertaken and no published cases involving loss of hearing due to sport noise were found. However, multiple cases involving industrial employees sustaining hearing loss due to excessive noise were identified. It is worth noting there may be pending litigation by fans or sport employees suffering from injuries because of loud noise caused in sporting events. The case below highlights the danger of excessive noise for employees and can be applied by analogy to the field of sports.

In a fairly recent case a judge outside of New Orleans Louisiana ruled in favor of five employees who sustained loss of hearing from years of working at their employer's oil refinery (Becker v Murphy Oil Corp, 2011). During the late 1970 s, the refinery owners failed to install noise abatement equipment during a $\$ 35,000,000$ plant expansion because they felt the $\$ 110,000$ cost to do so was too 
expensive. In 1980, Murphy Oil began conducting noise level surveys at which time their own expert acoustical engineer determined the noise levels were unsafe. In 1981, the company identified four areas of the refinery as major noise sources, but did nothing about it, again because of the expense. Tests conducted at three different times during the 1980s found the highest noise levels exceeded $100 \mathrm{~dB}$ and sound levels exceeded 85 dBA "even in the break area." In 1988, as a result of the discovery of maximum sound levels of 105-135 dB, a report by USF\&G (the refinery's insurance company) recommended the use of hearing protection inside the refinery. In 1989, a repeat study found readings over $90 \mathrm{dBA}$. The five plaintiffs were administered sporadic hearing tests during their employment, but in most instances they were not informed of the results. In addition, the plaintiffs were not informed of the precautions they should take. Apparently earplugs were available in the nurse's station, but only if an employee asked for them. Testimony during the trial indicated signs requiring the use of hearing protection were "intermittent, if at all" in some of the designated high noise areas (Beckerv Murphy Oil Corp., 2011).

In essence, Murphy Oil failed to implement the OSHA-mandated hearing protection and conservation program even though they knew the noise levels were a problem. The judge in the case determined "Murphy Oil did not provide a workplace free from excessive noise, regular and periodic hearing tests and warnings to employees of the dangers associated with long-term chronic occupational noise exposure" (CityBusiness Staff Reports, 2010, para. 5). The judge ordered the five plaintiffs to receive $\$ 50,000.00$ each, but the award could climb to $\$ 2$ million as 35 other former employees have also filed suit. Murphy Oil appealed the verdict and the Louisiana State Court of Appeals upheld the ruling of the trial court on July 7, 2011.

Individuals employed in the oil refinery industry obviously face different challenges than those involved in the business of sport. However, facility and event managers should realize commonalities do exist. Both industries have numerous employees and, as previously mentioned, loud environments exist during some sporting events. The volume of noise produced during NASCAR races, spinning bike classes and sold out athletic events can exceed acceptable ranges. Administrators responsible for these types of excessive noise settings need to be aware of the duty owed to their employees. In addition, sport administrators should also be aware of damage awards handed down in cases like Becker v Murphy Oil Corp. Otherwise failure to provide appropriate hearing protection, regular and periodic hearing tests, and warnings to employees of the dangers associated with long-term chronic noise exposure could result in similar awards.

The music industry has sustained its share of liability claims. In 2003, a 57-year-old male plaintiff filed suit claiming that while attending a concert put on by John Fogerty (ex-Credence Clearwater Revival lead singer) the music caused him to suffer a hearing impairment. The plaintiff alleged Fogerty's music was "unreasonably loud." The court stated it is commonly known loud music may cause hearing problems. They indicated the reasonable person standard applied and a concertgoer should appreciate that loud music could cause a hearing impairment. The court found the primary assumption of risk doctrine was appropriate and barred the plaintiff's action. The court went on to state it would be impossible for a jury to 
determine if the concert could be construed as "too loud" without knowing how loud it actually had been. The court also believed there was no standard of care owed to the plaintiff and as a result no jury could determine if the defendants had breached the duty. Finally, the judge opined that it wasn't the court's duty to determine what was "too loud"; that should be left up to the legislative branch of the government (Powell v Metropolitan Entertainment Company, 2003).

People choose to spend their leisure time and disposable income in a variety of ways. Many individuals go to professional sporting events, some head for the slopes, while others go to concerts. Some of these leisure activities are accompanied by bouts of excessive noise and the cumulative noise exposure from headphones, crowds, workout music, whistles and horns can be significant. As Beach et al. discovered $(2013 ; 2014)$ some individuals who attend one noisy event will often attend similar loud events, while others expose themselves to "binge listening." Any risk management plan that specifically relates to noise reduction in the workplace needs to take into consideration the collective noise in an employee's personal life and provide strategies to ensure the employee understands the potential ramifications. It is therefore incumbent upon sport organizations to adopt holistic and integrative risk management strategies to protect their employees and fans.

\section{Literature Review}

A comprehensive and systematic literature review has been conducted covering the most relevant publications on noise and its impact on individuals in sport facilities, as well as the workplace in general. In addition, the most important regulations pertaining to this topic have been examined and outlined.

The United States Labor Department's Occupational Safety and Health Administration (OSHA) regulates workplace safety across the United States. OSHA covers private sector employers and employees in all 50 states, the District of Columbia, and other U.S. jurisdictions either directly through Federal OSHA or through OSHA-approved state programs. State-run health and safety programs are required to be at least as effective as the Federal OSHA program (OSHA, 2013b). One of the many aspects of workplace safety regulated by OSHA is noise.

OSHA criteria include a permissible exposure limit (PEL) of $90 \mathrm{dBA}$ as an eight-hour time-weighted average (TWA). OSHA regulation 29 CFR 1910.95(b)(1) states when employees are subjected to sound exceeding OSHA permissible exposures, administrative or engineering controls shall be used to decrease the sound level. If those controls fail to bring the sound levels into the acceptable range, personal protective equipment (PPE) should be provided and used by the affected individual to reduce sound levels to an acceptable level. General estimates of work-related noises can be examined in Table 1. It should be noted that any noise exposure over $85 \mathrm{dBA}$ could result in hearing loss.

There are significant penalties for violation of OSHA regulations. For example, employers who willfully or repeatedly violate OSHA regulations may be assessed a financial penalty of not less than $\$ 5,000$ and not more than $\$ 70,000$ for each violation (OSHA, 2014b). 
Table 1 Estimated Decibel Levels of Common Work-Related Activities (NIOSH, 2001)

\begin{tabular}{lc}
\hline Activity & dBA \\
\hline Whisper & 30 \\
Normal conversation & 60 \\
Phone ring & 80 \\
Hair dryer / lawn mower & 90 \\
Bulldozer & 105 \\
Chainsaw & 110 \\
Ambulance siren & 120 \\
Jet engine & 140 \\
12-gauge shot gun & 165 \\
Rocket launch & 180 \\
\hline
\end{tabular}

\section{Noise-Induced Hearing Loss (NIHL)}

While a number of actions can prevent noise-induced hearing loss, little can be done once it has taken place. Hearing loss is the third most prevalent chronic condition among the elderly; it has also become common in most age groups (Vio \& Holme, 2005). The National Institute on Deafness and Other Communication Disorders (NIDCD) reported approximately 26 million Americans between the ages of 20 and $69(15 \%)$ have experienced hearing loss due to exposure to noise (Stump, 2013). Noise-induced hearing loss (NIHL) is $100 \%$ preventable, but is the second most common form of hearing loss next to age-induced hearing loss (Rabinowitz, 2000). NIHL symptoms are usually subtle in the early stages. Initial hearing loss tends to occur for high-pitched sounds only.

Most individuals are aware of the need to use earplugs when shooting a gun or working around loud machinery (i.e., lawn mowers, airplanes, industrial motors). However, many people do not realize their hearing may be damaged while conducting everyday activities. Loud noise damages the structures in the inner ear and can cause hearing loss and sound distortion (NIDCD, 2014). Noises such as lawn mowers, rock concerts, snowmobiles, or a jet during takeoff can cause serious damage to the ear. Power tools such as a weed-whacker can range in decibel level anywhere from 100-115 dB. These levels are similar to the levels found at a rock concert (NIOSH, 2001).

Anything over $120 \mathrm{dBs}$ tends to produce physical pain in the inner ear (ENT USA, n.d.). This pain is often associated with a ringing sensation in the ear or head. This problem is termed "tinnitus" and can be the first sign of impending hearing loss. Hearing loss is linked to psychological issues and can be extremely expensive to correct, if correction is even possible (Vio \& Holme, 2005). Another potential symptom brought about by intense noise is called temporary threshold shift (TTS). Mielczarek (2003) described the onset of TTS as, "If you listen to your car radio after an evening aerobics class and then are surprised the next morning at how loud 
the volume is, this is a sign you suffered from a temporary threshold shift after the aerobics class" (p. T5).

Results from one study indicated NIHL could occur within just a few minutes and up to a couple of hours after the overexposure occurs. At first, overexposure to noise will damage the hair cells within the ear. Once this has happened, it is then possible to damage the actual cell bodies within the ear. For some individuals, these hair cells will regrow and repair themselves, but for most people, the cell bodies cannot regrow once the damage has occurred (Kujawa \& Liberman, 2009).

\section{Noise in Sports Settings}

Sport Officials. Flamme and Williams (2013) examined sport officials regarding hearing loss. A survey was conducted of 321 sport officials who self-reported hearing conditions. Hearing loss was examined because sound levels produced by whistles range between 104 and $116 \mathrm{dBA}$. At $104 \mathrm{dBA}$ an umpire can face unprotected exposure for up to 90 seconds before damage occurs. However, at 116 dBA damage occurs after only five seconds of unprotected exposure. A majority of the officials (293 versus 27) were male. Minimal or moderate trouble hearing was specifically noted for officials who were between 60-69 years of age, while all age groups reported at least a little trouble hearing. The study specifically examined certain sports where the pervasiveness of whistle blowing might have impacted the officials' hearing. Women's volleyball, men's basketball, and football were some examples where the study examined the prevalence of whistle blowing based on the position (head official versus a linesman, back judge or other position) and the level (i.e., college versus high school) of officiating.

The sound from a whistle may remain over $80 \mathrm{~dB}$ at a distance of over 50 feet from the official who blew the whistle. However, sport officials are not just exposed to noise from whistles; crowd noise can remain at high levels for sustained time periods as well. NIHL can begin to occur for long-term exposure of $75 \mathrm{dBA}$. As mentioned, sport officials had a higher incidence of self-reported hearing troubles and tinnitus than observed in the general population. While not definitive, the research suggested whistle use may contribute to hearing loss among sport officials (Flamme \& Williams, 2013).

Stadiums and Arenas. An early study pertaining to sound levels at sports facilities was carried out by Axelsson and Clark (1995). They examined the sound at one hockey match and found average levels of $100 \mathrm{dBA}$ with a peak of $120 \mathrm{dBA}$. These levels are well over the OSHA PEL. Noise levels were also collected during game six of the 1987 World Series. The average was $97 \mathrm{dBA}$, which is a little over $90 \%$ of the OSHA PEL. These researchers were among the first to indicate spectators and employees at sports facilities should be involved with hearing conservation programs.

England and Larsen (2014) measured the noise levels at 10 intercollegiate basketball games to determine the impact of noise on hearing thresholds. The hearing thresholds of 20 participants were measured at the beginning of the games and an hour post-game to determine if any changes occurred. While the average noise intensities were within accepted standards for workplace exposure, the measurements indicated the sound levels were greater than acceptable intensity levels at 
six of the ten games. The authors recommended the universities warn their fans of the danger and offer earplugs to interested fans. The authors also suggested a hearing conservation program for staff working the games. These dangers increase the duty a facility manager has toward staff and spectators alike.

A study examined the noise exposure for individuals working in indoor hockey games. Noise samples were taken at a variety of semiprofessional hockey games at two different venues. Average noise levels for the two arenas ranged from 81-97 dBA, but peak levels ranged from 105-124 dBA. The games at both venues only lasted three hours, but the measurement device was normalized over an eight-hour period. The first arena had readings taken with a mean attendance average of 5,780 fans over three games (Cranston, Brazile, Sandfort, \& Gotshall, 2013). While 40\% of the monitored employees were exposed to $85 \mathrm{dBA}$ over eight hours, they were not exposed to a PEL of $90 \mathrm{dBA}$ for the eight hours. At the second venue the mean average attendance was 5,289 patrons over four games. Eleven of the 19 sampled employees (58\%) were exposed to sound levels that exceeded the $85 \mathrm{dBA}$ level for eight hours but, similar to the first group, they also were not exposed to a PEL of $90 \mathrm{dBA}$ for the time period (Cranston et al. 2013). Even though there were no OSHA violations, the authors recommended the employees be enrolled in a hearing conservation program. These types of programs educate employees regarding strategies and equipment that can minimize the harm associated with working in noisy environments. For example, personal protective equipment (PPE), such as earplugs, is often recommended in these programs and employees are taught the proper usage of such equipment.

Not surprisingly, it could be predicted that noise levels would be higher in an enclosed arena than an open-air stadium. In a 2010 study of three football stadiums the results indicated $96 \%$ of workers were exposed to noise levels over $85 \mathrm{dBA}$ and 39\% exceeded the OSHA action limit (Engard, Sandfort, Gotshall, \& Brazile, 2010). The stadium study was conducted during events with 19,721 to 75,703 fans compared with less than 6,000 fans in the previous study's two arenas.

A 2006 study of three National Hockey League (NHL) Stanley Cup playoff games collected sound readings ranging from 101-104 dBA during games lasting three hours. The subjects in the study reported symptoms of muffled hearing and mild ringing (tinnitus) in their ears. The authors reported that the hearing thresholds of the subjects decreased as a result of the excessive levels (Hodgetts \& Liu, 2006).

Events that include excessive noise levels are not consigned to only professional sports. Morris, Atieh, and Keller (2013) reported decibel levels as high as $118 \mathrm{dBA}$ at some of the larger intercollegiate basketball arenas. As discussed earlier these readings can prove dangerous. Therefore, from a risk analysis standpoint facility managers at university venues must also be aware and ready to mitigate these potential dangers for both spectators and employees attending NCAA events.

Vuvuzelas. Specific components of an athletic event can also impact noise exposure. Many fans bring noisemakers to the game. One of the most dangerous devices is not a cowbell or a drum, but an African horn called a vuvuzela. Traditionally made from a kudu horn, the three-foot long trumpet-like instrument was originally used to call people together to meet and is now part of the event experience in many soccer stadiums (Hall, Koekemoer, \& Swanepoel, 2010). The noise output created by such devices can average $131 \mathrm{dBA}$ at the horn opening 
and 113 dBA six feet from the opening. These devices can produce sounds up to $140 \mathrm{dBA}$, which is approximately the level of noise produced by a jet engine during takeoff (130-140 dBA). Since there could be thousands of vuvuzelas at a game the noise level can be significantly higher. Professional soccer matches have two 45-minute halves with a 15-minute intermission. Fans begin blowing their vuvuzelas before the matches begin and continue after play has ceased. As a result, many of these games last upwards of two hours and the din from vuvuzelas lasts as long. Workers exposed to more than 45 seconds per day at $113 \mathrm{dBA}$ and at a distance of six feet without hearing protection have exceeded the NIOSH recommendations for noise exposure, which may result in hearing loss or tinnitus (Kardous \& Morata, 2010a).

A study examined noise levels at South African Premier Soccer League (PSL) matches in Cape Town, South Africa during one match at a 40,000-seat stadium that was half-full and at a second sold out match at a 52,000-seat stadium (Petersen, Ramma, \& Singh, 2011). The researchers found the frequency range of the vuvuzela noise to be similar to that of common industrial noise. The study confirmed some PSL matches expose spectators (and logically event personnel) to unsafe noise levels. The authors indicated that due to the large crowds attending the matches many fans were in close proximity $(<1 \mathrm{~m}$ or $<3$ feet $)$ to the vuvuzela blower and risked overexposure due to the noise (Petersen et al., 2011).

Auto Racing. Noise is nothing new to NASCAR and other auto racing events. Automotive racing environments present noise levels often found in some of the loudest workplace settings. In the 1970s efforts were made to reduce the noise by installing mufflers, but the quieter cars were unpopular with racing teams and spectators (Kardous \& Morata, 2010c). The highest noise levels are found in the "pit" area where peak sound levels at three studied tracks reached and exceeded $130 \mathrm{dBA}$, often recognized as the human hearing threshold for pain (Kardous \& Morata, 2010b). However, those employees working in the pits are not the only ones exposed to the excessive noise. Fans and event personnel are exposed to a time-weighted average (TWA) of around $96 \mathrm{dBA}$ compared with drivers, who are exposed to $114 \mathrm{dBA}$. The length of time individuals are exposed to these noise levels depends on the length of the race, as well as weather and track conditions. A race could last anywhere from an hour and a half for a short-track dirt race to four hours for a long 500-mile race. In addition, it is not just race day exposure that represents a major concern. Those working in the industry are often exposed to loud noises throughout the week and might have 12-21 hours of intensive noise exposure every week for 40 consecutive weeks during the racing season.

In another study, researchers attempted to characterize the intensity, frequency content and duration of exposure to noise at a typical stock car race (Rose, Ebert, Prazma, \& Pillsbury, 2008). Data were collected during a major NASCAR event at the Lowe's Motor Speedway in Concord, North Carolina. Rose et al. (2008) found sound levels significantly less than levels associated with the potential for an immediate permanent threshold shift (PTS). However, individuals exposed in this setting were considered to be at risk for a temporary threshold shift (TTS). When considering individual patterns of exposure the authors stated, "While the risk for most fans attending a single stock car race is low, the overall cumulative exposure for drivers, crews, and track employees may be far greater" (p. 691). 
When considering an individual with age- or disease-related hearing loss and / or other environmental and occupational exposures, noise at motorsport automotive races may also contribute in an additive manner to NIHL.

\section{Aerobics Classes and Noise (Music)}

Sound-related hazards are oftentimes one of the most commonly overlooked hazards in fitness facilities. How many people put in earplugs before joining an aerobics or spinning class? How many instructors wear earplugs? Based on feedback from industry professionals, most instructors who teach aerobics and spinning classes end up listening to loud music for 30-90 minutes for each of their classes and many of these individuals teach three to four classes a day (Fried, 2009). The music played may come from a number of genres, but the common denominator for most of these classes is the intensity of the noise. In many cases the music is so loud the class participants cannot hear the trainer's cues. The instructor attempts to solve this problem by shouting over his/her microphone, which in turn makes the noise levels even more dangerous. In addition, repeatedly shouting over the music oftentimes results in the instructor going hoarse or even losing his/her voice. One study found $44 \%$ of their respondents partially or completely lost their voice during and after instructing. Having to shout instructions also caused increased sore throats, hoarseness and loss of voice unrelated to illness (Long, Williford, Olson, \& Wolfe, 1998).

Unfortunately, in most situations no one complains about the intensity of the music. Quite the contrary, many instructors and participants find the loud music enjoyable and helpful while motivating them during their exercise sessions. This quandary led the American Council on Exercise (ACE) to develop guidelines for safe music levels in fitness settings. As cited in Mielczarek (2003), the guidelines established by ACE for aerobics instructors stipulate the music levels in aerobics classes should be kept in the range of 70-80 db. The sound intensity during some spinning classes has registered $100-110 \mathrm{~dB}$ or $30-40 \mathrm{~dB}$ above ACE guidelines (Mielczarek, 2003).

A preliminary study in England investigated the impact of noise levels on an aerobics class (Nassar, 2001). Twenty-eight individuals participated in the experiment and hearing thresholds were collected on all 28 subjects. Fourteen subjects were placed in a control group and not exposed to any music (noise). The remaining 14 individuals were subjected to music with a mean noise level of $91.8 \mathrm{~dB}$ for 60 min. To maintain consistency, the noise levels in the aerobics class were monitored throughout the entire hour. Two minutes after the music ended hearing thresholds were collected a second time. All 14 subjects in the exposure group sustained various levels of TTS. Additional studies found noise levels during aerobics classes of 105 dBA (Center for Hearing and Communication, n.d.), 87.1 dBA (Torre \& Howell, 2008), $93.1 \mathrm{dBA}$ (Beach \& Nie, 2013) and $95.86 \mathrm{dBA}$ in a Brazilian indoor bike class (Palma, Mattos, Almeida, \& Oliveira, 2009).

Results from the previous studies indicate that even with established industry guidelines (ACE) fitness instructors continue to blast their music disregarding the potential hearing loss. While some individuals believe these employees need to be protected from themselves, others have confidence the dangers will be recognized before it is too late. Nevertheless, it may take threats from concerned participants 
to cause a shift in the current intensity of music in most aerobic and spinning classes. The safety of participants, employees and attendees should be of the utmost importance and is the responsibility of the fitness center manager.

\section{Entertainment and Leisure}

Individuals engage in a variety of activities for entertainment or relaxation purposes. Attending sporting events, concerts, and nightclubs are just a few examples of these types of events or activities. While they may appear unrelated they all share one commonality, a propensity for loud noise. More and more adolescents are exposed excessive noise while listening to loud music. Similar to the plaintiff's assertions in Powell v Metropolitan Entertainment Company (2003), the excessive sound levels result in hearing loss and tinnitus.

An early study from the 1990s reviewed the role of leisure noise on hearing. The author (Clark, 1991) coined the term nonoccupational or leisure noise. Clark indicated the most common sources for leisure noise emanated from exposure to live or amplified rock, classical, or jazz music; personal listening devices (i.e., Walkman or MP3 players); noise around the home, and hunting and target shooting (Clark, 1991). His research indicated that while all the identified activities had the potential for excessive levels of sound the most serious came from recreational hunting and target shooting.

Goggin et al. (2008) researched the noise levels experienced by both employees and patrons at entertainment venues. The authors investigated multiple components including knowledge of noise induced hearing loss (NIHL) education program, attitudes toward noise levels and hearing protection, use of hearing protection, experience of adverse effects and exposure times. The authors surveyed 303 patrons as well as measured noise levels in the venues. The majority $(81 \%)$ of the respondents reported a variety of hearing problems including temporary hearing loss, tinnitus and headaches. The data indicated the mean exposure time to be almost five hours and the mean sound levels were greater than $95 \mathrm{~dB}$. In addition, the use of earplugs by females and respondents under the age of 26 was minimal. Ironically, remembering the NIHL education program did not cause an increase in the use of earplugs.

A 2012 research study investigated noise-induced tinnitus (NIT), attitude toward loud music, and the factors influencing the use of hearing protection (HP) (Gilles et al., 2012). A survey was given to 145 university students. The results indicated almost $90 \%$ of the students had experienced tinnitus after listening to loud music and almost $15 \%$ had permanent NIT. The authors indicated that most of the students were not worried about the loss and few (11\%) wore hearing protection.

Beach, Gilliver, and Williams (2013) surveyed 1,000 Australians between the ages of 18-35 who engaged in a number of leisure activities (including concerts) where they were exposed to high levels of noise. The authors were not only interested in possible hearing damage as a result of attending these events, but also if the participants perceived the risks attached to the exposure. The data were collected via an online survey and the exposure to the high level noise fluctuated between 0-6.77 times the acceptable amount. The data indicated that if the respondents attended one noisy event they were more apt to attend others, especially concerts, bars and nightclubs. The results indicated a correlation between exposure to high 
levels of noise, early indications of hearing loss and a perception of the risk from the exposure.

A second, more recent, study by Beach, Gilliver, and Williams (2014) indicated $60 \%$ of the participants were exposed to normal noise levels, but $33 \%$ were involved in "binge listening." During these periods, usually on the weekends, participants were exposed to one or two high noise days followed by several days of low-level noise. The authors discovered the most prominent causes of high noise was attending a concert, playing a musical instrument in a band, or frequenting a nightclub. Average noise levels greater than $100 \mathrm{~dB}$ were recorded during each of these activities. The authors stated that additional research is necessary to determine if long-lasting exposure to high levels of noise is more or less harmful than binge listening.

\section{Risk Management Strategies}

The dangers of NIHL and tinnitus, as well as temporary threshold shift (TTS) and permanent threshold shift (PTS) have been described. Examples of hearing losses sustained by sport officials, stadium and arena employees, intercollegiate athletic department employees, NASCAR fans and drivers, as well as fitness employees and participants have been discussed. Many of these problems are preventable and opportunities exist to reduce or eliminate a number of them. Risk management is one option. Risk management has been defined as a proactive process that involves assessing all possible risks associated with the event and its stakeholders by strategically anticipating, preventing, minimizing, and planning responses to mitigate those identified risks (Leopkey \& Parent, 2009). Because the risk of injury in many sports is high, governing bodies and individuals involved with these sports have a responsibility to manage the risks at acceptable levels (Fuller, 2007). In recreation and sport, risk management has been used to combine the traditional corporate interest of limiting financial risk with the interest of the recreation or sport industry - by decreasing injuries, death and liability. By reducing injuries to participants, guests and employees, the company reduces its financial exposure. Thus, an effective risk management plan may help control and diminish the legal liabilities that confront today's recreation or sport managers. However, avoidance of litigation should not be the main goal of risk management program (Cotten, 2013).

It is not enough to be aware of the dangers associated with excessive noise. Once it has been identified steps must be taken to lessen or mitigate the possibilities of hearing loss. The steps are part of what is called "risk assessment." The stages used to create this plan will be similar regardless of the type of organization. These assessments identify both physical as well as financial risks for the organization, school or business. The identification stage is one of the key aspects in developing a successful risk management program. If a facility manager wants to control risks (such as elevated noise levels or poor usage of PPE) it becomes important to identify those hazards. In many cases primary and secondary factors exist that should be addressed to reduce the possibility of loss or injury. For example an NFL football official will contend with the noise from his whistle (primary), but depending on the proximity of the crowd the official may also have to contend with the volume of crowd noise (secondary). These factors should be addressed in the organization's standard operating procedures (SOPs) (Ammon, 2013). 
Powell v Metropolitan Entertainment Company (2003) was a good example of identifying a risk. While the court stated a concertgoer should appreciate that loud music could cause damage to a person's hearing the demographics of the attendees may still impact the venue manager's duty to warn. For example, if a young teenage girl was attending her first One Direction (latest pop boy band) concert she may not be aware of the dangers of the loud music. The duty to warn for that type of concertgoer is completely different than for the duty owed to a male in his late 20s attending his thirteenth Metallica concert. As previous research studies indicate (Beach et al., 2013; 2014) some individuals who attend one noisy event will often attend similar loud events. Therefore, even though an individual may choose to attend multiple events a facility manager should still provide earplugs for those interested. This type of strategy should also be implemented with sporting events. As previously discussed, researchers investigating the impact of noise on hearing thresholds at intercollegiate basketball games recommended the university warn fans of the danger and offer earplugs to interested fans. The authors also suggested a hearing conservation program for staff working the games (England \& Larsen, 2014).

Once the risks have been identified the second stage involves the proper classification of the risks pertaining to their severity and frequency. The classification stage establishes the degree of risk (severity) as well as the chance (frequency) of the risk taking place. The level of severity may be classified as "low," "moderate," "critical," or "catastrophic." The level of frequency may fluctuate between "low," "medium," and "high" (Ammon, 2013).

After the risks have been classified, a "treatment" is selected to assist in controlling or reducing the risk. The treatment will vary depending on whether the risk is financial (audiologist expense) or a bodily injury (hearing related concern). Treatments include "avoiding" the risk, "transferring" the risk, "retaining" the risk, or "reducing" the risk. The type of treatment depends on the components of the risk and its probability of occurring. Risks with a high level of severity or medium level of severity with a high level of frequency should be "avoided" completely or discontinued if they are presently being offered. Insurance is often used to "transfer" or shift the responsibility from the insured to the insurance company. Businesses that preserve the risks and assume financial responsibility for them are said to have "retained" the risk. Finally, an organization may attempt to diminish the identified risks utilizing "reduction" techniques. Examples of reduction strategies include well-maintained equipment, adequately trained staff, proper documentation and sufficient signage (Ammon, 2013).

An example of not implementing a necessary reduction strategy can be found in the Becker v Murphy Oil Corp. (2011) case. The company not only failed to implement federally required hearing protection, but they were also negligent in establishing a conservation program, even though they knew the noise levels were a problem. This omission resulted in a large compensatory award to the plaintiffs. As previously mentioned, when sound levels exceed acceptable ranges venue managers must reacted proactively regardless if the facility is an oil refinery, a fitness center, a stadium, an arena or a NASCAR track. Failure to implement proper reduction strategies, such as warnings to fans and spectators and earplugs to those who want them, could result in financial penalties. 


\section{General Prevention Strategies}

The data and studies presented regarding noise-induced hearing loss (NIHL) are of great concern. They suggest immediate intervention strategies are necessary not only in sports, but in any occupation where one is exposed to any kind of extreme or excessive noise. The American Academy of Audiology (2003) believes noiseinduced hearing loss can be prevented and that no one should have to experience a loss of hearing just to make a living. Occupational and environmental medicine (Daniel, 2007) recommends and OSHA requires a comprehensive hearing conservation program. OSHA requires it to include the following: (1) a monitoring program, (2) an audiometric testing program, (3) hearing protection, (4) employee training and education, and (5) recordkeeping (OSHA, 2013a). The critical roles and responsibilities of the audiologist in preventing noise-induced occupational hearing loss are delineated in the AAA's Position Statement on that issue (AAA, 2003).

Monitoring Program. The monitoring program consists of measuring the sound level and assessing the extent to which the exposure to noise is equal to or exceeds the action level $(85 \mathrm{~dB})$. According to the OSHA regulations (US Department of Labor, 2013), one of the first preventive actions is to conduct a survey in the facility where the noise is discovered to determine its location, sources and affected individuals. The key factors indicating the noise exposures are equal to or beyond the acceptable level include employee complaints, individual hearing loss, noisy conditions that make conversation difficult, and notification about specific machines that produce noise found to be intolerable. Implementing an annual monitoring program will help guarantee acceptable noise levels. Including all exposed employees in the hearing conservation programs will also assist in this endeavor (OSHA, 2014a). OSHA-supported state and private consultation organizations provide free on-site assistance to organizations that need it.

Audiometric Testing Program. Audiometric testing monitors the sharpness and acuity of an employee's hearing over time and also provides an opportunity for employers to educate employees about their hearing and the need to protect it. In fact, OSHA requires all employees whose exposures equal or exceed an 8-hr time-weighted average of $85 \mathrm{~dB}$ be tested during the first six months of their employment. Subsequently, they should be tested annually to determine if their hearing ability has changed (OSHA, 2014a). Properly trained personnel should carry out the audiometric testing program. In the absence of a trained professional, testing can be outsourced to specialized clinics and audiology practices. The noise time weight average (TWA) of employees should be kept in the employee medical files by the employer.

Hearing Protection. OSHA requires employers to provide employees with convenient PPE such as earplugs and earmuffs to use when the noise meets or exceeds $85 \mathrm{dBA}$. Employees with normal hearing should wear hearing protectors when the noise level reaches $90 \mathrm{dBA}$ while those with an identified standard threshold shift should use their PPE when the noise level meets $85 \mathrm{dBA}$. All protective devices should be provided to employees at no cost (Bassette, 2008). Organizations that fail to equip their employees with hearing protection tools when needed are in violation of OSHA standards. 
Employee Training. While employee training is recommended by OSHA and is essential for educating individuals about the noise-induced hearing loss phenomenon, there is no agreement on the most effective method and type of training. Group sessions facilitated by professionals in safety and conservation programs using multiple training aids such as videos, posters, and motivational materials have proved to be effective in the past (Bassette, 2008). However, oneon-one training sessions have recently been considered to be more effective as the training can be tailored to the case of every individual. Ross (2007) suggests the content of the training should be focused on the effects of noise including noiseinduced hearing loss, fatigue and distraction. The factors causing NIHL inside or outside the workplace have to be explained and the trainee needs to know how to select and use his/her PPE. Follow-up sessions need to be organized to make sure that protection devices are worn properly and regularly.

Recordkeeping. Employers are responsible for keeping records pertaining to their employees' exposure level to the noise, as well as the results of their audiometric tests. They are also required to post the OSHA hearing regulations at the worksite in an effort to make employees aware and responsible for their own health. According to Bassette (2008), when employees receive copies of their audiometric tests and they know what they mean at the time of the test, the noise-induced hearing loss decreases.

\section{Summary and Practical Implications}

The issues identified and strategies provided in this paper have implications for sports educators and employers. Instructors who teach sport management topics rarely, if ever, address noise and hearing-related concerns their students may face when working in the sport industry. Educators teaching courses such as event management and facility management should include a discussion with their students about the risks for employees, participants, and spectators and how those risks can be identified and managed. Sport management instructors may also wish to point out that sporting events are considered entertainment. Other entertainment preferences include events such as monster truck shows, NASCAR races and concerts. Each of these entertainment options includes their own hearing loss concerns.

Those who work in the industry also rarely think about noise exposure as a concern. The research highlighted in this article addresses several of the areas where noise may cause significant and permanent injury to attendees, participants, and employees working at sport venues and events. A study on sport officials found exposures from pervasive whistle blowing between 104 and $116 \mathrm{dBA}$. At $116 \mathrm{dBA}$ damage occurs after only five seconds of unprotected exposure and respondents in every surveyed age group reported some hearing loss (Flamme \& Williams, 2013). Decibel levels as high as $118 \mathrm{dBA}$ have been recorded during intercollegiate basketball games (Morris et al., 2013). Studies pertaining to NHL matches found average levels of $100 \mathrm{dBA}$ with a peak of $120 \mathrm{dBA}$ (Axelsson \& Clark, 1995). These researchers indicated their belief spectators and employees at sports facilities should be involved with hearing conservation programs. A second study at three National Hockey League (NHL) Stanley Cup playoff game collected sound readings ranging 
from 101 to 104 dBA (Hodgetts \& Liu, 2006). A third hockey study investigating noise exposure levels found peak levels ranging from 105 to $124 \mathrm{dBA}$ (Cranston et al., 2013). Finally, noise levels recorded at football stadiums indicated $96 \%$ of workers were exposed to noise levels over $85 \mathrm{dBA}$ and $39 \%$ exceeded the OSHA action limit (Engard et al., 2010).

While it is not illegal to expose athletes and fans to loud noises, employees have very specific and detailed protections dictated by federal regulations. Employers that do not take precautions to protect their employees may face significant fines, as well as cause considerable harm to their employees. Thus, every precaution should be taken by managers of sport venues and events to consider employee safety when planning for and managing an event. Practitioners should take a proactive approach in identifying potential issues and managing the safety of their environment, as opposed to a reactive approach once damage has occurred. Failure to provide the requisite warning may increase a facility manager's liability if a plaintiff can prove the manager knew of the risk and did nothing to mitigate it. If no conservation programs are implemented and the music continues to boom while the PA announcer consistently coaxes the fans to yell louder, then a venue manager's defense to a lawsuit will be severely hampered.

\section{References}

American Academy of Audiology. (2003). Position statement on preventing noise-induced occupational hearing Loss. Retrieved from http://www.audiology.org/resources/documentlibrary/Documents/niohlprevention.pdf

Ammon, R., Jr. (2013). Risk management process. In D.J. Cotten \& J.T. Wolohan (Eds.), Law for recreation and sport managers (6th ed., pp. 278-288). Dubuque, IA: Kendall/Hunt.

Axelsson, A., \& Clark, W. (1995). Hearing conservation programs for nonserved occupations and populations. Occupational Medicine: State of the Art Reviews, 10(3), 657-662.

Bassette, R. (2008). Getting serious about workplace hearing protection. Chemical Engineering Progress, 104(5), 35-39.

Beach, E., Gilliver, M., \& Williams, W. (2013). Leisure noise exposure: Participation trends, symptoms of hearing damage, and perception of risk. International Journal of Audiology, 52(S1), S20-S25. doi:10.3109/14992027.2012.743050

Beach, E., Gilliver, M., \& Williams, W. (2014). A snapshot of young adults' noise exposure reveals evidence of binge listening. Applied Acoustics, 77, 71. doi:10.1016/j. apacoust.2013.10.004

Beach, E., \& Nie, V. (2013). Noise levels in fitness classes are still too high: Evidence from 1997-98 and 2009-11. Archives of Environmental \& Occupational Health.

Becker v Murphy Oil Corporation, 70 So. 3d 885; 2011 La. App.

Center for Hearing and Communication. (n.d.). Noise in health clubs. Retrieved from http:// www.chchearing.org/noise-center-home/facts-noise/noise-health-clubs

CityBusiness Staff Reports. (2010, March 25). Judge rules in favor of former Murphy Oil workers. New Orleans CityBusiness. Retrieved from http://neworleanscitybusiness.com/blog/2010/03/25/judge-rules-in-favor-of-former-murphy-oilworkers/\#ixzz36QKWkoY7

Clark, W. (1991). Noise exposure from leisure activities: A review. The Journal of the Acoustical Society of America 90. 175. Retrieved from http://dx.doi.org/10.1121/1.401285

Cotten, D.J. (2013). Negligence. In D.J. Cotten \& J.T. Wolohan (Eds.), Law for Recreation and Sport Managers (6th ed., pp. 42-53). Dubuque, IA: Kendall/Hunt. 
Cranston, C.J., Brazile, W., Sandfort, D.R., \& Gotshall, R.W. (2013). Occupational and recreational noise exposure for indoor arena hockey games. Journal of Occupational and Environmental Hygiene, 10(1), 11-16. doi:10.1080/15459624.2012.736341

Daniel, E. (2007). Noise and hearing loss. The Journal of School Health, 77(5), 225-231. doi:10.1111/j.1746-1561.2007.00197.x

Dolich, A. (2014, October 6-12). Can you hear me now? Stadium noise hits damaging levels. Street \& Smith's SportsBusiness Journal, 17(25), 29.

Engard, D.J., Sandfort, D.R., Gotshall, R.W., \& Brazile, W.J. (2010). Noise exposure, characterization, and comparison of three football stadiums. Journal of Occupational and Environmental Hygiene, 7(11), 616-621. doi:10.1080/15459624.2010.510107

England, B., \& Larsen, J.B. (2014). Noise levels among spectators at an intercollegiate sporting event. American Journal of Audiology, 23(1), 71-78. doi:10.1044/10590889(2013/12-0071)

ENT USA. (n.d.). Noise and hearing loss. Retrieved from htttp://www.entusa.com/noise_ hearing_loss.htm

Flamme, G.A., \& Williams, N. (2013). Sports officials' hearing status: Whistle use as a factor contributing to hearing trouble. Journal of Occupational and Environmental Hygiene, 10(1), 1-10. doi:10.1080/15459624.2012.736340

Fried, G. (2009). Fitness facility safety: How safe are fitness facilities for workers? Journal of Legal Aspects of Sport, 19(1), 35-65.

Fuller, C.W. (2007). Managing the risk of injury in sport. Clinical Journal of Sport Medicine, 17(3), 182-187. doi:10.1097/JSM.0b013e31805930b0

Gilles, A., De Ridder, D., Van Hal, G., Wouters, K., Kleine Punte, A., \& Van de Heyning, P. (2012). Prevalence of leisure noise-induced tinnitus and the attitude toward noise in university students. Otology \& Neurotology. Retrieved from http://eenenaloor.be/sites/ default/files/Gilles_etal_2012_UniversityStudents.pdf

Goggin, L.S., Eikelboom, R.H., Edwards, G.S., Maric, V., Anderson, J.R., . ... (2008). Noise levels, hearing disturbances, and use of hearing protection at entertainment venues. Australian and New Zealand Journal of Audiology, 30(1), 50-58. doi:10.1375/audi.30.1.50

Hall, J.W., Koekemoer, D., \& Swanepoel, D.W. (2010). Vuvuzela—good for your team, bad for your ears. South African Medical Journal, 100(2), 99-100.

Hodgetts, W.E., \& Liu, R. (2006). Can hockey playoffs harm your hearing? Canadian Medical Association Journal, 175(12), 1541-1542. doi:10.1503/cmaj.060789

Kardous, C.A., \& Morata, T. (2010a, June 17) Vuvuzelas: What's the buzz? NIOSH Science Blog. Retrieved from http://blogs.cdc.gov/niosh-science-blog/2010/06/vuvuzelas/

Kardous, C.A., \& Morata, T. (2010b, August 16). High speeds, higher decibels. NIOSH Science Blog. Retrieved from http://blogs.cdc.gov/niosh-science-blog/2010/08/racecars/

Kardous, C.A., \& Morata, T. (2010c, August 18). NIOSH: NASCAR racing can be louder than factories. ISHN Magazine. Retrieved from http://www.ishn.com/articles/nioshnascar-racing-can-be-louder-than-factories-8-18

Kujawa, S.G., \& Liberman, M.C. (2009). Adding insult to injury: Cochlear nerve degeneration after "temporary" noise-induced hearing loss. The Journal of Neuroscience, 29(45), 14077-14085. doi:10.1523/JNEUROSCI.2845-09.2009

Leopkey, B., \& Parent, M. (2009). Risk management issues in large-scale sporting events: A stakeholder perspective. European Sport Management Quarterly, 9(2), 187-208. doi:10.1080/16184740802571443

Long, J., Williford, H.N., Olson, M.S., \& Wolfe, V. (1998). Voice problems and risk factors among aerobics instructors. Journal of Voice, 12(2), 197-207. doi:10.1016/S08921997(98)80039-8

Matador Sports. (2011). Closed-captioning coming to a stadium near you. Business Insider. Retrieved from http://www.businessinsider.com/closed-captioning-coming-to-astadium-near-you-2011-4 
Mielczarek, E. (2003, July 10). Aerobics class noise unfit for ear. The Washington Post, p. T5.

Morris, G.A., Atieh, B.H., \& Keller, R.J. (2013). Noise exposures: Assessing an NCAA basketball arena on game day. Professional Safety, 58(8), 35-37.

Nassar, G. (2001). The human temporary threshold shift after exposure to 60 minutes' noise in an aerobics class. British Journal of Audiology, 35(1), 99-101 Retrieved from http:// cat.inist.fr/?aModele=afficheN\&cpsidt=921353.

National Institute for Occupational Safety and Health (NIOSH) (2001). General estimates of work-related noises. DHHS (NIOSH) Publication No. 2001-104.

National Institute on Deafness and Other Communication Disorders (NIDCD). (2014). Noise-induced hearing loss. Retrieved from http://www.nidcd.nih.gov/health/hearing/ pages/noise.aspx

Occupational Safety and Health Administration (OSHA). (2013a). 29 CFR 1910.95(b) (1).

Occupational Safety and Health Administration (OSHA). (2013b). Who OSHA covers. Retrieved from https://www.osha.gov/workers.html\#3

Occupational Safety and Health Administration (OSHA) (2014a). 29 CFR 1910.95(g) (1).

Occupational Safety and Health Administration (OSHA). (2014b). Penalties. Retrieved from https://www.osha.gov/pls/oshaweb/owadisp.show_document?p_table=OSHACT\&p_ id $=3371$

Palma, A., Mattos, U.A., Almeida, M.N., \& Oliveira, G.E. (2009). Level of noise at the workplace environment among physical education teachers in indoor bike classes. Revista de Saude Publica, 43(2), 345-351. doi:10.1590/S0034-89102009000200016

Petersen, L., Ramma, L., \& Singh, S. (2011). Vuvuzelas at South African soccer matches: Risks for spectators' hearing. Noise \& Health, 13(50), 71-75. doi:10.4103/14631741.73995

Plontke, S., \& Zenner, H.P. (2004). Current aspects of hearing loss from occupational and leisure noise. GMS Current Topics in Otorhinolaryngol Head Neck Surgery. 3. Retrieved from http://www.ncbi.nlm.nih.gov/pmc/articles/PMC3199798/

Powell v Metropolitan Entertainment Company, 762 N.Y.S.2d 782; 2003 N.Y. Misc.

Rabinowitz, P. (2000). Noise-induced hearing loss. American Family Physician, 61(9), 2749-2760 Retrieved from http://hannaziegler.tripod.com/ent/varia/rabinowi.pdf.

Rose, A.S., Ebert, C.S., Prazma, J., \& Pillsbury, H.C., III. (2008). Noise exposure levels in stock car auto racing. Ear, Nose, and Throat Journal, 87(12), 689-692.

Ross, P. (2007). Hearing conservation: Effectively preventing noise-induced hearing loss. Professional Safety, 52(6), 52-59.

Stump, E. (2013, Winter). (Sound's) dual personality. Sound harms as well as heals; balance both traits for healthy hearing. Hearing Health, 26-31. Retrieved from http://online. qmags.com/HH0113?pg=26\&mode=2\#pg26\&mode2

Torre, P., \& Howell, J. (2008). Noise levels during aerobics and the potential effects on distortion product otoacoustic emissions. Journal of Communication Disorders, 41(6), 501-511. doi:10.1016/j.jcomdis.2008.02.002

U.S. Department of Labor. (2013). OSHA laws and regulations. Retrieved from https:// www.osha.gov/law-regs.html

Vio, M.M., \& Holme, R.H. (2005). Hearing loss and tinnitus: 250 million people and a US $\$ 10$ billion potential market. Drug Discovery Today, 10(19), 1263-1265. doi:10.1016/ S1359-6446(05)03594-4 